\author{
Charles Spence ${ }^{1}$ and Ophelia Deroy ${ }^{2}$ \\ ${ }^{1}$ Crossmodal Research Laboratory, Department of Experimental Psychology, \\ University of Oxford OX1 3UD, Oxford, UK \\ ${ }^{2}$ Centre for the Study of the Senses, Institute of Philosophy, \\ University of London, London, UK
}

Address correspondence to:

charles.spence@psy.ox.ac.uk

ophelia.deroy@gmail.com

\title{
On the shapes of flavours: A review of four hypotheses
}

\begin{abstract}
Does it make sense to talk about a round wine, or a sharp taste? Many chefs and wine writers certainly seem to think that it does. The historical precedent of 'the man who tasted shapes', as well as recent claims that the chemical senses could present us with forms of universal synaesthesia (Stevenson and Tomiczek 2007), make it natural to wonder whether there might not be a widespread form of synaesthesia underlying these surprising reports. Alternatively, however, they might instead reflect nothing more than the metaphorical use of language (cf. White 2008). Intriguingly, a new field of experimental research is now starting to demonstrate many examples where tastes, aromas, flavours, and the oral-somatosensory attributes of foods and beverages are reliably matched to particular shapes. These crossmodal matches are thus both ubiquitous and robust across the general population, or at least within the cultures in which they have been tested to date. After discussing a number of these examples of the crossmodal matching of shape (or shape attributes such as angularity) to food and drink stimuli, we argue that the category of crossmodal correspondences best captures the core of the phenomenon that is at stake. What is more, they may help to explain why the use of such cross-sensory pairings by chefs, food
\end{abstract}


companies, marketers, and designers can be particularly effective. The focus on this specific type of cross-sensory matching demonstrates that it is a much more robust empirical phenomenon than it might at first seem, both because of its extensive use out there in the marketplace, and also because of the theoretical issues it raises about the differences between several plausible alternative explanations of crossmodal associations.

Keywords: shapes; taste; aroma; flavour; oral-somatosensory; cross-modal.

'Sight by itself informs us only of colors and forms. No one can pretend that the images of sight are determinate in reference to taste. They are, therefore, so far general that they are neither sweet nor non-sweet, bitter nor non-bitter, having savor nor insipid' (Peirce 1868).

\section{Introduction}

The chef Paul Bertolli who, until 2005, was the executive chef and co-owner of the Oliveto restaurant in Oakland, California (see Bertolli 2003), has talked of his use of the shapes inspired by flavours and combinations of foodstuffs when designing certain of the food menus served at his former restaurant. One example of this shape-inspired approach to cuisine is highlighted in Figure 1. There, one can see how the chef puts together the various courses that go to making up a meal in terms of the angularity of the shapes (or should that be landscapes) that those dishes, and the wines that are paired with those dishes, inspire in his mind. Starting with the house-cured sausages with bitter lettuces and Lambrusco, a combination that, according to Bertolli at least, is both sharp and extremely pointy. As the meal progresses, one can see how the shapes that are matched to the dishes gradually become smoother.

What are we to make of Bertolli's approach to menu design? At first sight, it might strike one as bizarre: After all, house-cured sausages are not literally sharp or pointy, but long and round. Obviously, then, the shape that is at stake here in the construction of one of Bertolli's menus is not the actual shape that the food normally takes. So, if sausages are not literally pointy, where - one might ask - does the angularity illustrated in Figure 1 come from? One suggestion as to what may be going on here is that the chef might be a synaesthete. That is, Bertolli could be one of those rare individuals who experience idiosyncratic additional conscious experiences, often sensory in nature, that are typically not shared by the rest of the population (see Cytowic 1993; Cytowic and Eagleman 2009). However, the principle problem 


\title{
The Shape of a Menu
}

\author{
Four Types of House-Cured Sausages (Salame \\ Toscano, Genovese, Mortadella, Coppa di Testa) \\ Bitter Lettuces \\ N.V. Lambrusco, Barbolini \\ $\sim$ \\ Maccheroni al Sugo di Carne \\ 1999 La Sagreta Rosso, Sicilia \\ $\sim$ \\ Halibut with Fresh Porcini Mushrooms \\ 1997 “Batar," Querciabella \\ Fricasee of Rabbit \\ 1998 Chardonnay, "Kleinstein,"Santa Maddalena \\ Budino of Pears with Almonds \\ 1997 Orvieto, "Calcaia," Barberani
}

Sometimes I think of a menu as having a graphic shape. This menu might look like this:

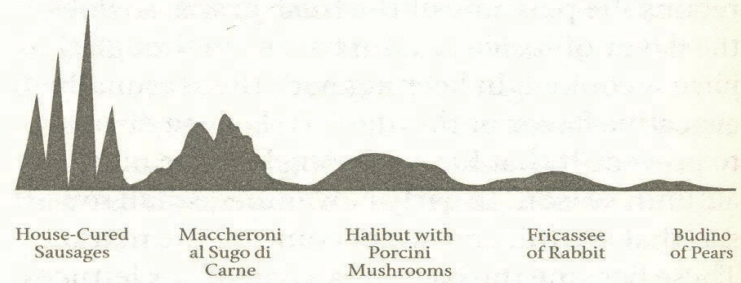

Figure 1. A shape-inspired menu from the chef Paul Bertolli (2003: 242)

with this interpretation comes from the widespread character of such shapefood associations in the general population and the lack of any evidence that they are accompanied by a vivid conscious experience of shapes when tasting dishes, as we detail in Part 2. An alternative hypothesis, one that is reviewed in Part 3, is that the attribution of shapes to tastes and flavours might simply be meant metaphorically. This hypothesis, besides its lack of explanatory power, also faces difficulties when it comes to trying to explain the range of behaviorial effects which are now being documented during the presentation of congruent combinations of shapes and tastes/flavours, and which are reviewed in Part 4. As shown in Part 5, the category of crossmodal correspondences - and the closely connected notion of shape symbolism are theoretically more robust in terms of encompassing these effects and also 
connect better with the utilization of specific shape properties to connote specific attributes in the food and beverage sector, illustrated in a variety of marketing and gastronomic contexts.

\section{Taste-related synaesthesia}

A quick search of the empirical literature reveals a number of documented cases of what has been called taste-shape synaesthesia. ${ }^{1}$ The individuals described in these research papers literally experience shapes (either seen or, more commonly, felt) in response to particular tastes or flavours that are either physically present, or else perhaps merely imagined (e.g., Cytowic 1993; Cytowic and Wood 1982; Spence and Gallace 2011; see Figure 2). According to the synaesthetic hypothesis, when the chef Paul Bertolli tastes a certain dish, he not only has a taste and/or flavour experience just like the rest of us but he also has an additional vivid sensory experience of a shape in his mind's eye, or perhaps he might 'feel' the shape in his mind's hand instead (cf. Kosslyn, Behrmann, and Jeannerod 1995). ${ }^{2}$

The case of one famous taste-shape synaesthete, at least initially seems close to that of Bertolli when, for instance, reporting cooking according to his synaesthetic associations. Michael, a synaesthete who first came to the attention of his neighbour, the neurologist Richard Cytowic, several decades ago, when he described cooking a roast chicken for a party until it took on a form with enough points on it. As he put it, 'you see, chicken is pointy' (see Cytowic 1993: 66). For this synaesthete, then, flavours, or perhaps orthonasal aromas (as when sniffing the food in the oven), gave rise to tactile shape/material concurrents that he experienced in his right hand: The flavour of spearmint, for example, apparently felt like smooth cool glass columns (see Day 2011: 388).

Note, however, that what researchers have called 'taste-shape synaesthesia' is probably better described as 'flavour-shape' synaesthesia, since it is normally flavours, such as the distinctive flavour of roast chicken in the case of Cytowic's, famous synaesthete, that trigger the concurrent experience of specific shapes/forms, rather than simple basic tastes, such as, for example, sweetness or sourness (see Cytowic 1993; Spence and Gallace 2011; though see also Cytowic and Wood 1982).

2 Note that it shouldn't necessarily matter that the majority of diners are unable to appreciate the 'changing landscape/shapes' of one of Bertolli's meals, since is has been shown that even non-synaesthetes often find the crossmodal stimulus combinations experienced by synaesthetes to be generally pleasing (e.g., Ward et al. 2008a). Whether the same is true in the world of taste and flavour synaesthesia is, currently, an open question. 


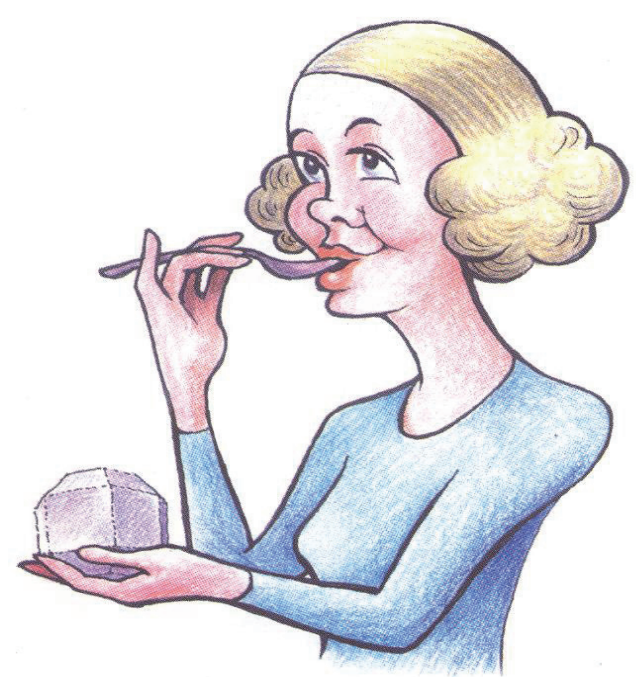

Figure 2. Schematic illustration of the kind of complex 3D haptic shape impression reportedly elicited by a specific taste/flavour in one synaesthete (Cytowic 1993: 66). Note that the shape is not experienced in the mouth, where the inducing taste or flavour is localized, but in the synaesthete's left hand instead

'Oh, dear $[\ldots]$ there aren't enough points on this chicken. [...] I know it sounds crazy, but I have this thing, see, where I taste by shape. [...] Flavors have shape, [...] I wanted the taste of this chicken to be a pointed shape, but it came out all round. [...] Well, I mean it's nearly spherical, [...] I can't serve this if it doesn't have points.' (the synaesthete Michael quoted in Day 2011: 392-393).

Other synaesthetes, meanwhile, have reported seeing colours when tasting foods (e.g., Ginsberg 1923; Myers 1911). Typically, the shapes or colours that such synaesthetes describe do not bear any obvious relation to the stimuli that have induced them. That is, to the real shape or colour of the food or flavour (as in the Paul Bertolli case mentioned above). Interestingly, such unusual sensory experiences can occur between pretty much any pair of sensory modalities, they can even be induced by linguistic stimuli: So, for example, some synaesthetes report experiencing taste sensations whenever they either read or hear specific words (e.g., Day 2011; Ward and Simner 2003): For instance, one young man quoted in Ward and Simner (2003: 241) reported that the name 'Phillip' tasted of "oranges not quite ripe", while the word 'safety' tasted of "toast lightly buttered". Other synaesthetes talk 
of experiencing tastes and/or flavours when they happen to listen to a certain piece of music or even when they hear a single musical note (Beeli et al. 2005; Cytowic 1993; Ferrari 1907; Luria 1968).

Another famous synaesthete, the Russian mnemonist "S.", described by Luria back in the 1960s, experienced a wide variety of different taste/ flavour sensations in response to different sounds: When, for example, he was presented with a $50 \mathrm{~Hz}$ tone (corresponding approximately to a G1), he reported experiencing a taste that he likened to sweet and sour borscht "a sensation that gripped his entire tongue". Meanwhile, when a $3000 \mathrm{~Hz}$ tone (i.e., close to a G7) was presented, he reported "an ugly taste - rather like that of a briny pickle" instead (Luria 1968; cf. Huysman 1884: 133-135).

It is, though, relevant to note here how extremely rare taste/flavour-shape synaesthesia is in the general population (Day 2005, 2011). Furthermore, the relation between the inducing stimulus and the concurrent experience is typically unique to the individual concerned in the sense that the strange pairings are experienced by the synaesthete and likely by no one else. So, while roast chicken might be experienced as pointy to a synaesthete like Michael (see Cytowic 1993), it will feel like the rounded hills of the rabbit dish drawn by Bertolli to another (for examples of the unusual sensory concurrents elicited by tastes/flavours as experienced by the synaesthete Sean Day, see http://www.daysyn.com/sean-syn-foods-and-odors.html downloaded on 09/03/2012). It is partly the idiosyncratic nature of the concurrent that makes it so difficult for another synaesthete, or for the rest of the non-synaesthetic population, to really have any sense of what it is that the synaesthete experiences.

Synaesthesia, this rare condition, has certainly attracted more than its fair share of attention from both the press and from those researchers who have attempted to uncover the neural basis for such surprising experiences (e.g., Cytowic and Eagleman 2009). However, without conducting the appropriate psychological tests, it turns out to be very difficult, if not impossible, to determine whether or not someone like Paul Bertolli is actually a genuine synaesthete. Certainly, a quick visual inspection of his book Cooking by Hand doesn't seem to reveal anything else to suggest that he is a synaesthete. That said, it is not all that uncommon for chefs to describe themselves as being (or having been) synaesthetic, as for example, in the case of Homaro Cantu, one of the Chicago School of modernist chefs (see http://superchefblog. com/2012/02/07/homaro-cantu-interview/ downloaded on 29/02/2012). One does, though, have to be rather careful here given that others use the term rather more loosely in order to refer to their own particular method 
of cooking (e.g., Gagnaire and Gonzales 2010; see also Marinetti 1930/1989; Spence and Piqueras-Fiszman, in press).

However, while it has informally been suggested that creative types (such as, presumably, chefs) might be more likely to be synaesthetic than are the rest of the mostly non-synaesthetic general population (e.g., Ramachandran and Hubbard 2001b, 2003; Ward et al. 2008b), more often than not, closer inspection of the available evidence has revealed this to be fashionable aspiration amongst those concerned rather than necessarily a genuine crosswiring of an individual's senses (see Harrison 2001). Furthermore, a quick look at the actual language used by Bertolli in Figure 1 also suggests that synaesthesia is most probably not the correct explanation for what is going on in his particular case: Note that he says that he 'sometimes' experiences shapes when cooking or thinking of a meal. By definition, a synaesthete will always experience the vivid concurrent in response to a given inducing stimulus (see Deroy and Spence 2013). The risk here is that we may end up loosening the specificity of the term synaesthesia to such an extent that it no longer means anything. The term itself is certainly seductive and it surely sounds more appealing to have synthetic perception than to have compartmentalized senses (Weiss 2002). However, using the term synaesthesia in order to label those individuals who use shape descriptors but do not experience systematic concurrents, we would argue, distorts the scientific definition of synaesthesia.

And, finally here, when describing the meal illustrated in Figure 1, he continues ' ...this fruit dessert follows the motif established by the preceding courses and their wines: a gradual diminishment of flavour intensity and concentrated flavors that open out to progressively softer and more calming ones.' (Bertolli 2003: 242). This statement may suggest that Figure 1 should perhaps be read as some sort of time-intensity plot, something that will be familiar to those working in the field of sensory science (e.g., Cliff and Noble 1990; Davidson et al. 1999), with the intensity of the taste or flavour experience being plotted on the $\mathrm{Y}$-axis and time running along the $\mathrm{X}$-axis. According to such an interpretation, the apparent shape-attributes might merely reflect any time-varying change in the intensity of the various tastes or flavours in each of the dishes (and the paired wines) over time. As such, we are still left with the question of why it should be that flavours might be expressed in terms of shape attributes. A readily available answer here is to consider this as nothing more than merely a kind of metaphorical transfer instead. 


\section{From tastes to shapes: The metaphorical hypothesis}

As we have seen above, in the absence of the results of behaviorial tests or consistent reports of systematic and vivid sensory concurrents, associations between shapes and tastes or flavours cannot easily be placed in the synaesthesia category. What we are left with is rather a way of expressing or thinking about - one domain of experience in term of another. This, then, sounds like a traditional definition of metaphor (e.g., Lakoff and Johnson 1980; see also Liu and Kennedy 1997). Here, it is important to stress that cookbooks like Paul Bertolli's are not the only place where tastes or flavours can be seen to inspire shape descriptors. One also comes across a widespread use of shape descriptors in the world of fine wine (e.g., Lehrer 2009). That is, wine writers often talk of well-rounded wines or of wines that are sharp. The famous French oenologist Emile Peynaud once stressed the importance of shape in both the perception and evaluation of fine wines: 'However lacking in imagination he might be, when a taster works the wine in his mouth and feels it with his tongue, he absorbs not only sensations of taste, but also impressions of volume, form and consistency. He forms a physical image of the wine... A wine is judged by this evolution in its form, and when it starts in one way and finishes in another, it is said not to taste homogeneous, to lack unity or to taste disjointed' (Peynaud 1996: 220).

Wine experts often seem to be convinced that talking about shapes for shapeless liquids like wine makes perfect sense, and that it says something important about the flavour of a wine. Anyone, wrote Peynaud, 'who has tasted Jurancon, the sweet wine from the Pyrenees foothills, will understand Orizet when he writes: 'It is the contradictory nature of Jurancon to be rounded at one end and pointed at the other' (Peynaud 1996: 220). Is such use of shape terms compatible with the hypothesis of a merely metaphorical use of language, as when, for example, one describes a cheese as having a sharp taste (see Marks 1991; Spence, Ngo, Percival, and Smith 2013; Williams 1976)? Or is it, as suggested by some, a form of conceptual synaesthesia or ideaesthesia, which underlies apparently arbitrary associations between conceptual dimensions (Gómez Milan et al. 2013; Walker and Walker 2012, see Woods et al. 2013, for discussion). It is certainly true that many people use sensory metaphors in order to help them convey experiences that they might otherwise find it very difficult to express. In this case, it seems as though resorting to shape descriptors (an external attribute that everyone can see, feel, and thus, presumably, also share) can help to convey an experience that is both highly individual and might otherwise be hard 
to describe. ${ }^{3}$ The same can be observed in other domains as well: So, for instance, people typically do not attempt to describe unfamiliar odours in terms of their sensory qualities, but will instead talk about their likely source (e.g., when someone says 'that smells like coffee and chocolate'). People will occasionally resort to other attributes, such as when talking about heavy or light fragrances, or fresh and green perfumes (Baudelaire 1857; Deroy, Crisinel, and Spence 2012; Velasco et al., submitted): Once again, though, the comparisons here are borrowed from the senses of vision or touch, senses whose associated experiences we find it much easier to communicate in terms of (who knows whether this fact is perhaps linked to the greater cortical real estate given over to processing information in these senses, see Gallace et al. 2012).

However, the question remains here as to why such metaphors 'speak' to us all? If we do not all spontaneously generate crossmodal associations between tastes/flavours and shapes in the way that Paul Bertolli and Emile Peynaud do, nevertheless most of us at least know what to expect in terms of a wine's sensory characteristics when someone else describes it to us in terms of it being 'rounded', or a particular cheese as tasting 'sharp' (Spence et al. 2013). One interpretation here, inspired by the work of Rader and Tellegen (1987), is to consider that only the individuals who produce these reports enjoy vivid concurrent experiences of shapes while tasting foods, but that the strength of the association is also shared by the rest of us, perhaps just with less vivid mental imagery (see also Spence and Deroy 2013, on this theme).

However, unless one can show that the association requires conceptual or linguistic mediation, there is no reason to believe that it has to be metaphorical. Another explanation, equally compatible with the fact that everyone understands talk of round and sharp tastes, appeals to the category of crossmodal correspondences (Deroy and Spence 2013; Spence 2011, 2012). As detailed below, the benefit of categorizing the phenomenon is to unveil and at the same time explain a rich array of associations which exist between shapes and tastes or flavours, and go beyond the few that surface in language.

3 After all, some researchers claim that we all live in different taste worlds (see Bartoshuk 1980). 


\section{The new science of corresponding shapes to tastes/flavours}

Until a couple of years ago, all that there was to document the existence of shape-taste associations was anecdotal reports, like those that have been mentioned so far in this piece. However, in the last few years, there has been a rapid growth of a now substantial body of psychological research that is now starting to demonstrate rather convincingly both the ubiquity of such crossmodal matchings (or correspondences) between shapes and the tastes, aromas, flavours, and oral-somatosensory attributes of a variety of everyday food and drink items and their robustness.

The methods used to establish the existence of such crossmodal matchings are frequently exceedingly simple, and are often based on forced choice tasks administered to groups of no more than 10 to 30 participants (e.g., Deroy and Valentin 2011; Gallace, Boschin, and Spence 2011; Ngo et al. 2011; Ngo and Spence 2011; Spence and Gallace 2011). Researchers are now also starting to harness the power of the internet in order to assess the shape matches made by different groups of individuals (e.g., from different countries or cultures; Ngo, Piqueras-Fiszman, and Spence 2012; Ngo, Velasco, Salgado, Boehm, O'Neill, and Spence 2013; Woods, Spence, Butcher, and Deroy 2013). In the latter case, participants are normally asked to imagine the taste/flavour associated with the consumption of familiar foods and beverages such as, for example, dark and milk chocolate, or carbonated and still water. Internet-based testing, together with field testing in some increasingly remote regions (Bremner et al. 2013) is currently allowing researchers to extend their theoretical accounts of shape-taste/ flavour matching beyond the undergraduates from Western, Educated, Industrialised, Rich and Democratic cultures (WEIRD, for short) that have been tested in the majority of laboratory research that has been published to date (see Henrich et al. 2010). Such research is also starting to turn up some surprising findings.

The results of some of the first research to have been conducted in this area by the Crossmodal Research Laboratory in Oxford, for example, has demonstrated that people normally associate milk chocolate with rounded abstract shapes, whereas darker cocoa chocolates tend to be more strongly associated with sharper, more angular shapes instead (Ngo et al. 2011). Interestingly, a rather different pattern of results has been reported in the Himba of Kaokoland in rural Namibia (see Bremner et al. 2013). ${ }^{4}$ This

4 Bremner et al. (2013) found that while the Himba match the sound of the word 'kiki' to an angular shape while picking a rounded shape as matching the sound of the word 'bouba', 
crossmodal matching presumably reflects the fact that sweet tastes are normally associated with round shapes (e.g., a circle) whereas bitter tastes (as found in high cacao dark chocolates) are frequently associated with angular shapes, such as a star (see Dichter 1971; Spence and Ngo 2012). Interestingly, these cross-sensory associations appear to be transitive, that is, they extend to other associations with sounds and names (see Figure 3): Meaningless words like 'maluma' (Köhler 1929, 1947; Usnadze 1924, 1927) and 'bouba' (Bremner et al. 2013; Ramachandran and Hubbard 2001b) are matched both with more rounded shapes and, in Western populations at least, with milk chocolate. Meanwhile, angular shapes such as 'takete' or 'kiki' are matched with bitter-tasting foods such as dark chocolate. We would like to argue that transitivity is not a property of metaphors, but rather a property of sensory mappings and associations (e.g., Stevens 1966).

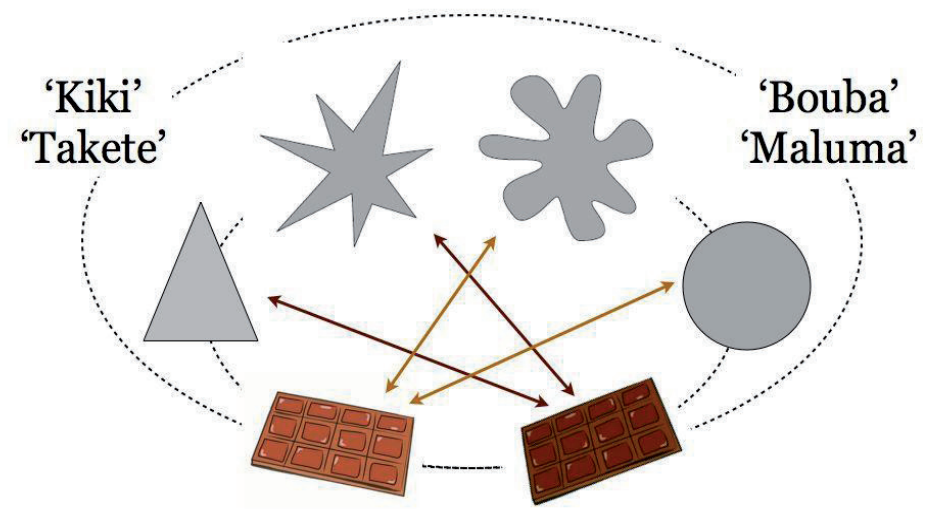

Figure 3. Schematic illustration highlighting some of the crossmodal correspondences that have been documented over the last few years between chocolate and shape in a group of western participants tested in the UK (taken from Ngo et al. 2011). As indicated, darker (i.e., more bitter) chocolate samples are matched with more angular shapes; while milk chocolate is matched to more rounded shapes instead. Such crossmodal correspondences appear to be bidirectional (Deroy and Spence 2013). They also extend to the speech sounds that are usually associated with angular and rounded shapes - the latter association falls within the remit of research on the topic of sound symbolism (Spence 2012)

they showed no bias to match carbonated water with an angular shape. When it came to chocolate, the Himba actually matched darker (i.e., more bitter) chcolate with rounded shapes, the opposite of the pattern that has been documented in Western participants. 
Deroy and Valentin (2011) also pioneered the investigation of crossmodal correspondences between shapes and flavours to the area of beers. These researchers had their participants taste three beers (Adelscott, Bitburger, and 1664 Blanche) and match them to a shape, to be chosen from amongst a wide set of 2D and 3D shapes (see Figure 4A). The participants in this French study tended to associate sweeter beers with more rounded and voluminous shapes, while matching more acidic beers with flatter shapes instead (see Figure 4B). Additionally, the more carbonated the drink, the more edges the shape that was chosen by the participants (see also Ngo et al. 2012). These results once again help to emphasize the fact that the shape association for a given taste or flavour normally does not emerge from

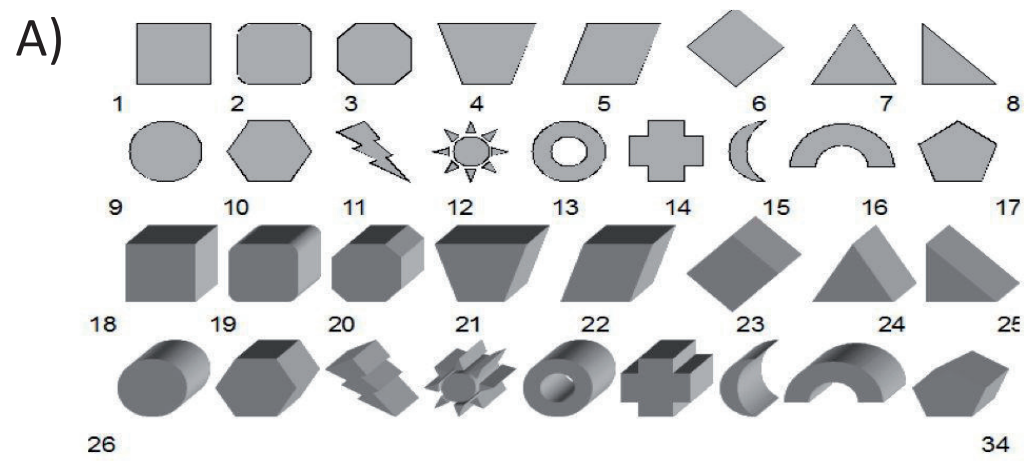

B)

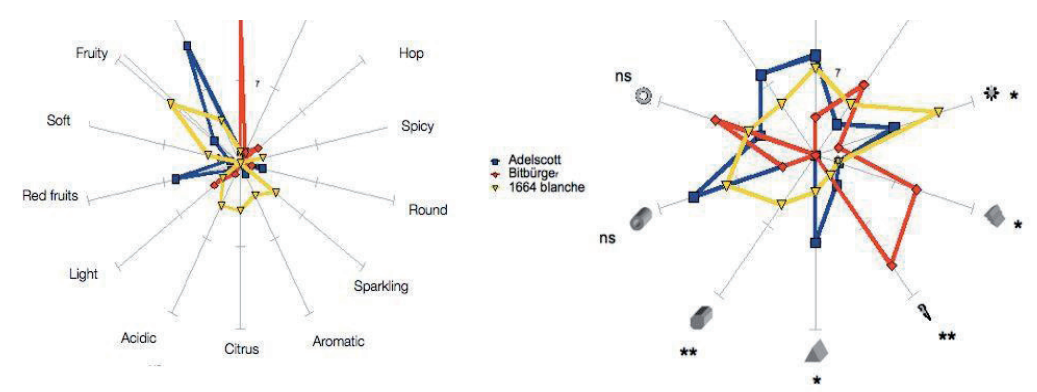

Figure 4. A) The 32 different shapes that participants chose from when matching to the taste/flavour of the three beers tested (and tasted) in Deroy and Valentin's (2011) recent study; B) Note how the different flavour profiles of the three beers (Adelscott, Bitburger, and 1664 Blanche) correlate with different shape properties. This figure, redrawn from Deroy and Valentin (2011), illustrates how the various sensory attributes of a drink such as beer (including both the taste and carbonation of the beverage) help to constrain the shape associations that people make 
any inference regarding the shape that the food itself typically has (though, that said, it is perhaps worth bearing in mind here the overrepresentation of angular red logos and designs on the labelling of beer; see Spence 2012a). The most interesting aspect of the study, though, comes from the subtle correlations between aspects of the complex beer flavour and the shapes that were chosen by the participants: This suggests that the correspondences might be much more fine grained than merely the sharp-round distinction that tends to surface in linguistic reports. Note that this fineness of grain is a characteristic of perceptual representations (Evans 1982).

Ngo et al. (2013) recently conducted a cross-cultural study of shapeflavour associations using a range of more or less exotic fruit-juices including pineapple, lulo, guanabana, passion fruit, mango and feijoa. The British and Colombian participants who took part in this study had to taste each of the juices and then fill in a series of pencil-and-paper line scales. Once again, the results revealed that those juices that were rated as tasting sweet and low in sourness were consistently matched with rounder shapes and speech sounds, sounds with a lower pitch, and were generally liked more (see Figure 5 ). By contrast, those juices that were rated as tasting sour were consistently matched with angular shapes, sharper speech sounds, sounds with a higher pitch, and were liked less.

Not only can people match shapes to the taste, flavour, and oralsomatosensory attributes of a food, such as its carbonation, they can also match the orthonasal aromas associated with various foodstuffs to specific shapes. So, for example, the participants in a seminal study conducted by Seo et al. (2010) had to match each of eight food odours (consisting of guava, honey melon, mint, parmesan cheese, pepper, truffle, vanilla, and violet) with one of 19 different abstract symbols, varying in shape from those that were more organic to those that were more angular. The participants reliably matched certain shapes to each of the odours (see Figure 6): As Seo et al. put it (p. 176): "The odors generally regarded as being pleasant (e.g., vanilla, banana, violet, honey melon, and mint) were paired with circle- or curveshaped symbols. Whereas, the odors judged generally as being unpleasant (e.g., parmesan cheese, truffle, and pepper) were paired with square- or angular-shaped symbols". 

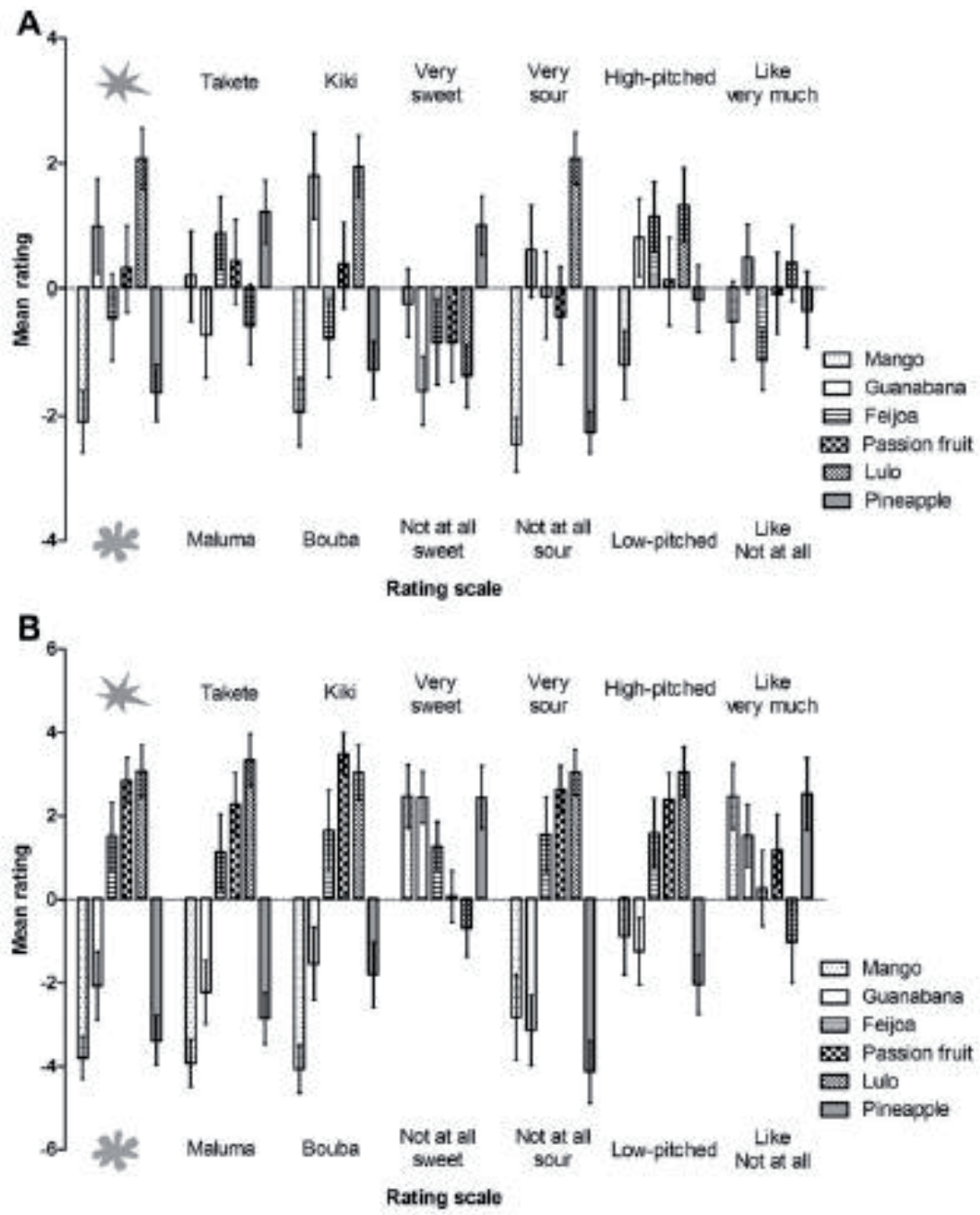

Figure 5. Participants' mean ratings for each juice and scale type in Colombian (A) and British participants (B). Note that negative values correspond to the organic shape, 'rounded' speech sounds (maluma and bouba), and low sweetness, sourness, and pitch, while positive values correspond with the angular shape, 'sharp' speech sounds (takete and kiki), and high sweetness, sourness, pitch, and liking. Error bars represent the standard errors of the means 


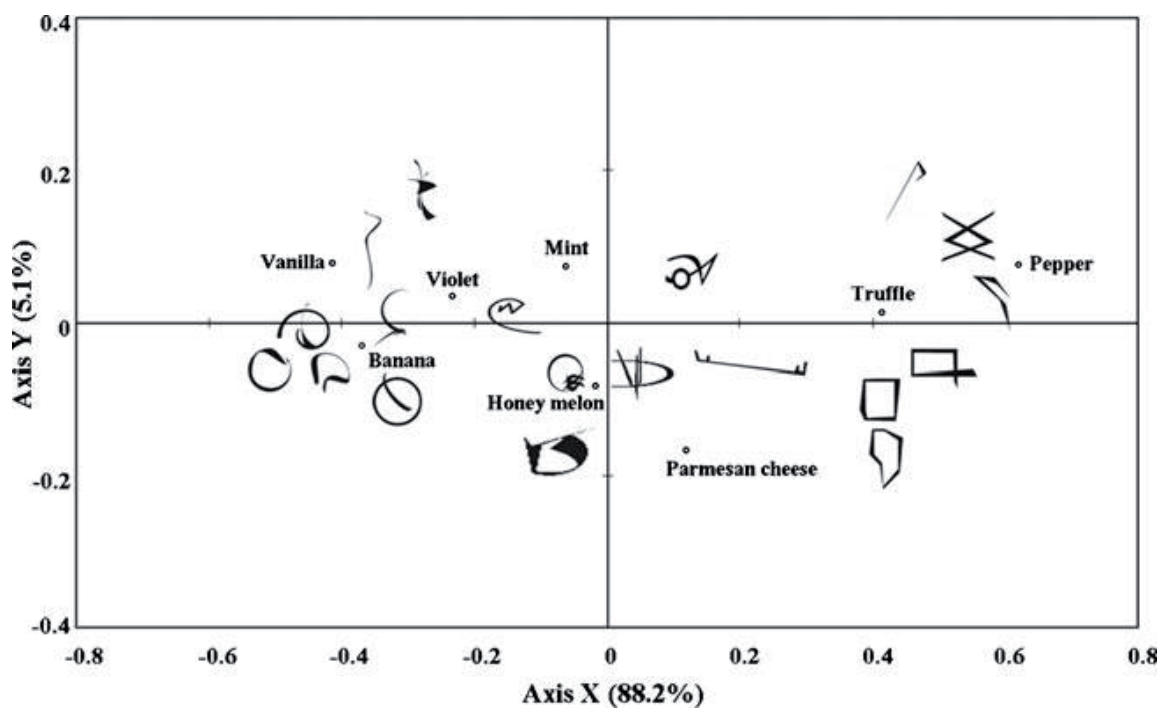

Figure 6. Results of Seo et al.'s (2010) study demonstrating that people match abstract shapes to a range of food aromas in a non-random manner. The participants were presented with 8 odours and viewed a series of 19 abstract symbols/shapes, one by one. The participants were instructed to answer the question, "Does this odor fit this symbol?" via "yes" or "no" answers

Hanson-Vaux, Crisinel, and Spence (2013) have followed up on Seo et al.'s (2010) research on the matching of shapes to retronasal odours. Once again, they presented a wide range of food aromas but this time they simplified the shape properties that the participants had to choose between (see the response scale utilized by participants in Figure 7A). Hanson-Vaux et al.'s results demonstrated that participants picked angular shapes more frequently for certain odours, while picking more rounded shapes as matching a number of the other odours (see Figure 7B).

Now it is important to note that many foods, such as, for example, cheese, wine, and coffee, possess a range of distinctive olfactory, gustatory, and oral-somatosensory qualities. As such, one might wonder whether each of these sensory attributes would be matched with a different shape and, if they were, whether one sensory attribute of the foodstuff may dominate in terms of controlling the overall shape association with a particular foodstuff. Spence et al. (2013) conducted what is perhaps the first study to address this question. In particular, they examined the different shape associations that people made in response to the orthonasal smell, the taste/ flavour, and the oral-somatosensory texture of various aged farmhouse 
cheeses (see Figure 8). The participants rated each sensory attribute of the cheese using a single response scale anchored at one end by a rounded shape and at the other by an angular shape. Significant differences in shape symbolism were observed across the cheeses that were tested. The results revealed that participants' crossmodal correspondences were based primarily on the taste, rather than the orthonasal smell or oral-somatosensory texture of the cheeses. That said, only further empirical research will tell whether this is a generalized pattern, or whether instead, the sensory attribute that dominates may change as a function of the particular foodstuff that happens to be under consideration. In any case, if confirmed, such patterns of dominance of certain sensory qualities over others are another aspect that makes shape associations in the area of food and beverages appear closer to a sensory phenomenon rather than to some form of metaphorical transfer.

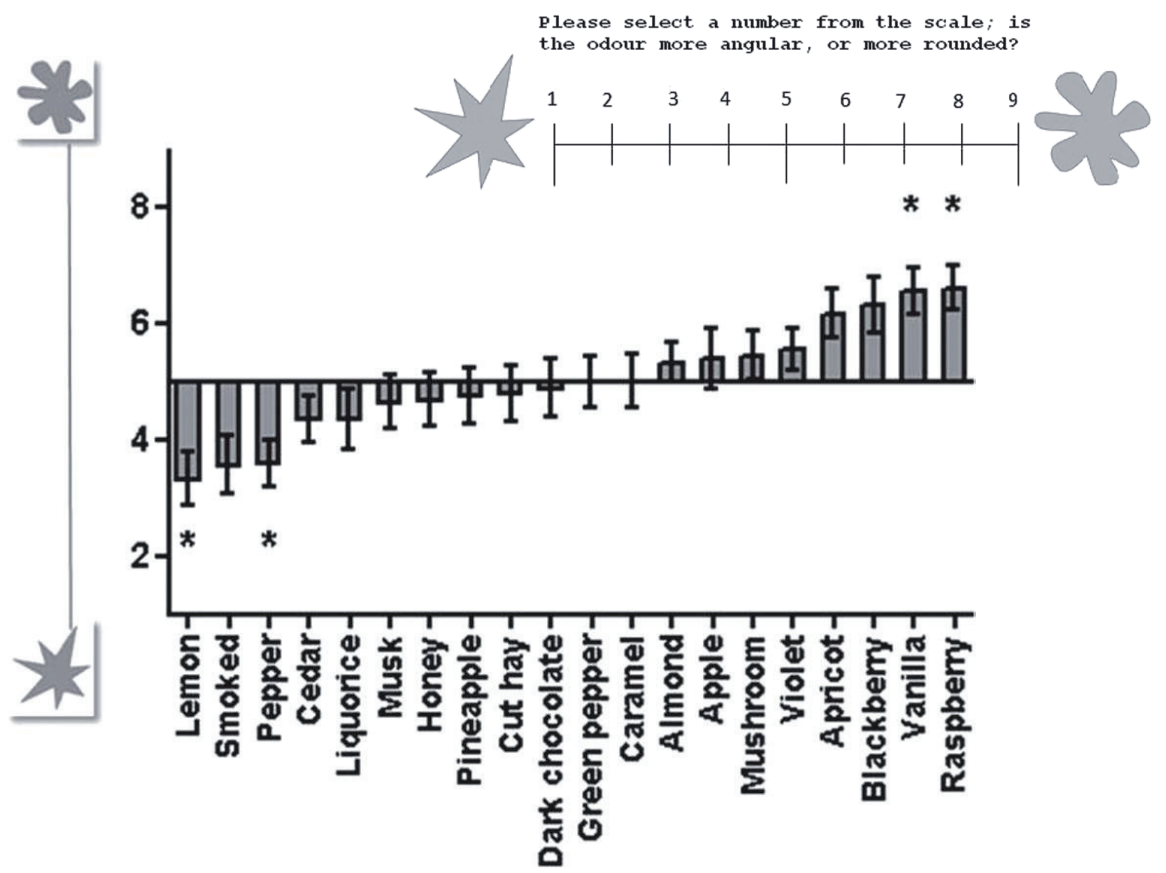

Figure 7. Results of a study by Hanson-Vaux et al. (2013) demonstrating that people will match shapes to a range of retronasal odours in a seemingly non-random manner. A) Shape response scale; B) Results showing that different odours are matched with a different degree of angularity 


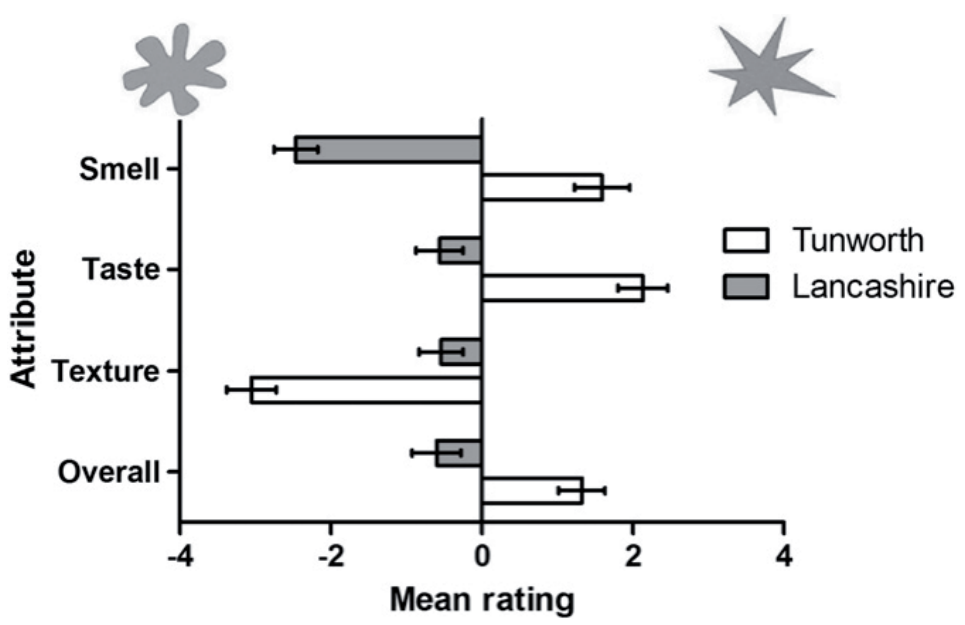

Figure 8. Mean ratings for the aroma, taste, oral-somatosensory texture, and overall experience of the Kirkham's Lancashire and Tunworth cheeses tested in Spence et al.'s (2013, Experiment 2) recent study. Kirkham's Lancashire is a semi-hard cow's milk cheese with a creamy, fresh milk smell, a lactic and buttery taste, and a texture that is yielding but slightly particulate, described by the cheesemaker as a 'buttery crumble.' The batch selected for the experiment was four months old. The Tunworth was chosen for its assertive sulphurous, cabbage-like flavour and earthy smell. It is a Camembert-style cheese that had been aged for around 7 weeks. It has a moist and creamy texture. The error bars represent the standard errors of the means.

\section{Interim summary}

Taken together, the latest results reported in this section demonstrate that it is not just the food and wine experts such as Paul Bertolli, Emile Peynaud, and a few others who match shapes to tastes or flavours. Nor is it only those rare individuals who happen to experience synaesthetic concurrent shapes in response to tastes/flavours. Instead, the matching of shapes to tastes and flavours is something that we are all capable of, even if few of us systematically experience vivid shape concurrents in response to particular tastes/flavours - the distinctive feature that separates synaesthetes from the rest of us (Deroy and Spence 2013). The crossmodal correspondences between shapes and tastes and flavours also present distinctive characters, such as transitivity, fineness of grain, and patterns of dominance, which separate them from metaphorical transfers. 
What is more, it appears that the correlations, or crossmodal correspondences, between food and shape-attributes are quite complex and deserve further careful empirical investigation. Four rules appear to emerge from the recent studies mentioned above:

- First, shapes are robustly and consistently correlated with specific attributes of foods and beverages (for instance, sweetness goes with rounded shapes, while carbonation goes with angularity; see Deroy and Valentin 2011; Spence and Ngo 2012);

- Second, the crossmodal correspondences that have been documented to date between shapes and tastes/flavours appear to follow a complex mapping, and vary with, for instance, the intensity of sweetness - the sweeter the food, the more voluminous and rounded the shape. It is thus likely that the relative intensity of the sensory attribute under consideration plays some role in determining the results of such crossmodal matches. That is, the same sweet food will probably be associated with more or less rounded shapes depending on what other foods and shapes it happens to be contrasted with (see Crisinel, Jones, and Spence 2012);

- Third, these crossmodal correspondences are likely to be bidirectional. That is, if sweetness is found to match best with roundness, roundness will likely also be matched best with sweetness (Deroy et al. 2013);

- Last but by no means least, shape and flavour correspondences find some extensions in other modalities or dimensions, for instance, matching tastes, aromas, and flavours with colours (Ngo et al. 2012; Spence et al. 2010) and sounds (Crisinel and Spence 2010, 2011, 2012; Holt-Hansen 1968, 1976; Knöferle and Spence 2012; Mesz et al. 2011, 2012; Ngo et al. 2011; Piesse 1891; Rudmin and Cappelli 1983).

These crossmodal correspondences involving shapes, tastes, flavours, and textures raise an important challenge to experimental psychologists, as they are more difficult to study than audio-visual correspondences (e.g., Evans and Treisman 2010; Parise and Spence 2012). However, they also have a number of potentially important applications, some of which are best illustrated, or found, in the food and beverage market. 


\section{Choosing better food shapes: Crossmodal congruence and shape symbolism}

As stressed earlier, a characteristic feature of synaesthesia is that it leads to a systematic conscious manifestation (the concurrent) during the presentation of a single stimulus (the inducer). By contrast, crossmodal correspondences can have effects on conscious experience in those situations in which two stimuli are presented (and which may either correspond crossmodally or else be mismatched). This said, the difficulty here, just as for the case of synaesthesia, is to check whether what people report really expresses a difference in their conscious perception, or whether instead the documented phenomenon exist only at the level of judgment (e.g., perhaps as some sort of response bias). One of the first suggestions that the shape one sees really could modify the taste and/or flavour of food came from a laboratory study conducted by Gal et al. (2007). These North American researchers conducted an experiment in which participants were required to judge which of three simultaneously-presented, and similarly-sized, shapes (either rounded or angular; see Figure 9) occupied the largest surface area.
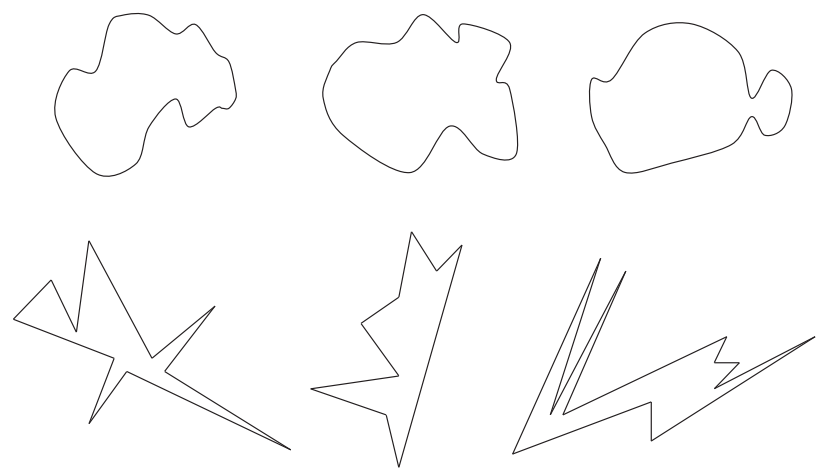

Figure 9. The shapes that participants had to look at in a study reported by Gal et al. (2007). A) Three rounded shapes; or B) Three angular shapes. The question that participants were asked prior to tasting a sample of cheese was "Which of the three shapes has the largest surface area?"

Next, the participants were given a small piece of cheddar cheese to taste. Intriguingly, those participants who had just been looking at the angular shapes rated the cheese as tasting around 7\% sharper than another group of participants who had just evaluated three organic shapes instead. Such results need to be handled with care before we conclude that there has 
been a crossmodal influence. Varying the shape of the food in a dish might enhance certain of its sensory features either at the perceptual level, analogous to the way in which sounds can affect the perception of visual objects, or by having a priming effect and simply biasing a person's judgments instead. The former explanation receives more support from recent results that have been collected by researchers working out of China (see Liang, Roy, Chen, and Zhang 2013). These scientists have very recently documented an influence of staring at angular shapes on participants' taste perception thresholds, at least when they were evaluating relatively weak taste stimuli (see Figure 10). Detection, in this case, provides stronger evidence than merely the effects on subjective reports of sweetness intensity.

A)
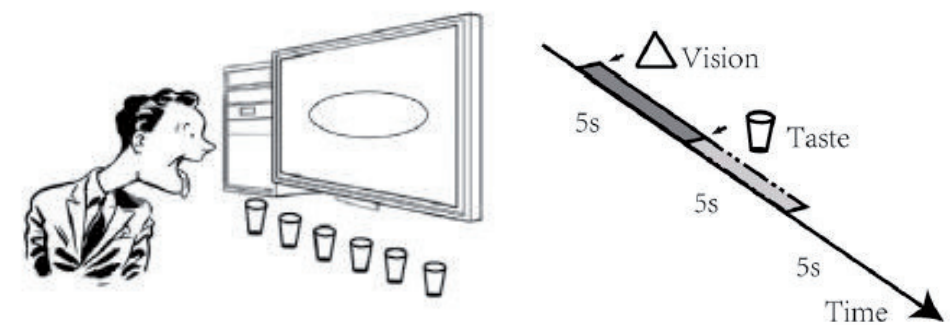

B)

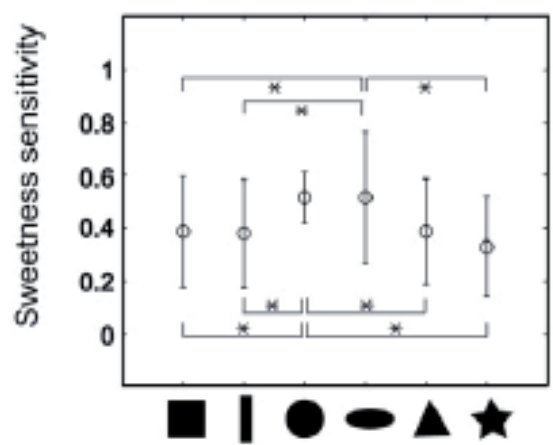

Figure 10. Results of a study by Liang et al. (2013) demonstrating that visuallypresented shapes influence sweetness sensitivity. The empty circles indicate the sweet detection ratios averaged across participants. The error bars denote the standard deviations across participants. The Y-axis represents the sweetness detection ratio (from 0 to 1 ), 1 represents $100 \%$ sweetness detection. The six icons presented along the X-axis indicate the various shapes that were displayed in front of the participants during the experiment. * indicates significant difference assessed by means of a pairwise t-test $(\mathrm{p}<0.05)$. 
Another kind of influence combines perceptual and judgement effects. The presentation of crossmodally corresponding stimuli can lead to an effect of congruence, which then impacts the overall judgment of the quality of the dish or product. Seo et al. (2010), for instance, conducted a study in which the odours of violet and parmesan cheese were presented together with an abstract shape that had been judged as being congruent (see above), with a shape that had been judged as incongruent, or else with no visual stimulus. Intriguingly, significant differences in odour pleasantness and intensity ratings were documented as a function of the visual shape stimulus that was presented. The odour of violet was rated as being more intense and more pleasant while parmesan odour was rated as being less pleasant when presented with a congruent as compared to an incongruent symbol. Thus, the pairing of a congruent shape with the odour gave rise to a more extreme perceptual response in terms of the participants' ratings of its intensity and pleasantness. In other words, those odours that were considered pleasant to begin with became more so, and more intense, when presented together with the congruent symbol. By contrast, those odours that were individually rated as unpleasant became more unpleasant with the presentation of the congruent symbol. The repertoire for acting on flavour is all the more important given that the pairing of shapes and flavours does not stop with the shape of the actual foodstuff itself as arranged on the plate. An interesting area of research that has recently started to open up here concerns the shape of the very plate on which a food is served. Why should a chef or restaurateur choose a round plate rather than a square plate, say, on which to serve one of his or her dishes? When asked about this, most chefs normally respond by saying that there is either no particular reason, or else they state that they base their decisions on intuition or gut feeling.

Preliminary testing conducted at the Institute Paul Bocuse in Lyon, France has provided some intriguing evidence to suggest that the rules of crossmodal correspondences might actually guide these choices, and shows that the shape of the plate really can impact significantly on a diner's appreciation and perception of a complex starter. In this study, the researchers gave diners in a restaurant-like setting a small raviolo with foie gras, served in a spicy chicken stock on a plate that was either round or square: The food was reportedly as tasting significantly better when served on the round plate than on the angular plate. Meanwhile, in a seminar given in 2011 at Oxford University's Department of Experimental Psychology, Julia Simner reported on a study that had been conducted together with Jamie Ward and others in which food presented on a star-shaped plate was rated as tasting 
significantly more bitter than the same food rated from a round plate (see also Day 2011: 383).

In a very new study, this time conducted by Stewart and Goss (2013), participants tasted a piece of cheesecake off of a black or white plate that could be either round or square. These North American researchers found that their participants rated the dessert as significantly sweeter (by 20\%) when tasted off the round white plate than from any of the other three plates. The effects on flavour intensity were even more dramatic, attracting ratings that were $30 \%$ higher when served off the round white plate than when served from any of the other plates.

That said, the possible influence of variations in plate shape on the perception of a dish of food needs to be handled with care. It would certainly be wrong to think that changing the shape of the plate will necessarily always change the taste or flavour of the food served from it, or even bias judgements. For example, Piqueras-Fiszman et al. (2012) compared the effects of eating a strawberry mousse from a plate that was round, square, or triangular (see Figure 11). In this study, conducted at the Alicia Foundation in Spain, changing the shape of the plate didn't exert any effect on the perceived sweetness of the mousse. Perhaps in this case though one might want to point to the fact that the angular plates used by Piqueras-Fiszman and her colleagues still had somewhat rounded corners, which might have softened any shape symbolic influence. Perhaps more importantly, though, the food itself had been made into a very angular form, and hence it is entirely possible that the angularity of the food itself (which was constant across the three plates) may have been foregrounded in the participant's mind against the background of the plate's shape. Given such uncertainty over the most appropriate interpretation of some of the results that have been reported to date, more research needs to be done here with neuroscientists, chefs, and plateware designers working hand-in-hand to develop plateware whose form can be used to bring out the intended flavour of the food.

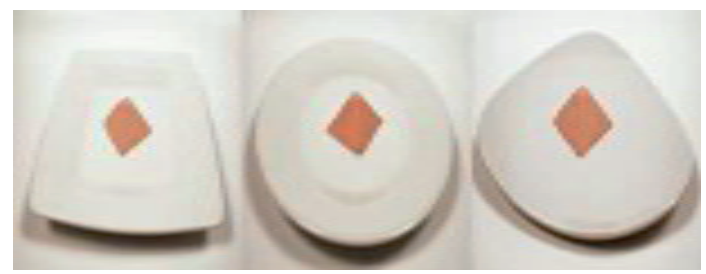

Figure 11. The three different shapes of plate used by Piqueras-Fiszman et al. (2012). Note the angular presentation of the food itself which may have dominated over the varying shape of the plate on which the dessert was served 
Here it is worth noting that similar effects of congruence need to be taken into account when it comes to the shapes of logos on product packaging, and even the shape of food packaging itself: This is a particularly important area of research, and one in which there is growing interest (see Becker et al. 2011; Overbeeke and Peters 1991; Spence 2012; Spence and Ngo 2012; Wang and Sun 2006). Here, though, crossmodal correspondences between shapes and tastes point toward another form of effect, usually documented in the domain of audio-visual correspondences under the name of sound symbolism. Traditionally, the terms 'sound symbolism' and crossmodal correspondences are used interchangeably to talk about the intuitive matchings that people make between certain shapes and sounds - and the same equivalence is true of shape symbolism and crossmodal correspondences in the domain of food. However, one should be sensitive to the differences between those cases in which viewing, or staring at a shape improves (or at the very least alters) the taste/flavours of the food that one is eating because of a feeling of crossmodal congruence or perceptual expectation and situations where, like in the case of symbolism and labels, shapes are used to refer to absent tastes and flavours. Whereas the first kinds of cases only require a binary relation (either the joint presentation of the two sensory cues, or a causal relation where one cue acts as a primer for the second), the notion of shape (or sound) symbolism needs a ternary relation - where one cue refers to another in virtue of the interpretation of an intention to mean something or to indicate something, which can be potentially absent. The difference is well marked in philosophy but less often stressed in psychology (e.g. Grice 1957). However, it highlights a possible difference between cases of shaped foods and uses of shapes as symbols on labels (or ideograms) in order to refer to absent tastes and flavours.

\section{Accounting for correspondences between the sensory attributes of foods and beverages and shapes}

Several plausible accounts have been put forward in order to try and account for the reliable crossmodal correspondences that have now been documented between the sensory attributes of foods and beverages and shapes. Julia Simner, for example, has suggested that the matching of sweetness to roundness or sphericity and sourness with shapes having a square or cubelike shape may be innate (see Day 2011: 383; though see also Gómez Milan, Iborra, de Cordoba, Juarez-Ramos, Artacho, and Rubio 2013). In terms of the underlying neural substrates supporting such crossmodal mappings, Sean 
Day (2011: 393) has pointed to the fact that the primary gustatory cortex, which is commonly considered to be the first cortical site to be involved in the perception of taste, lies directly behind the primary somatosensory area (S1). The suggestion here, then, is that, much like the neural crossactivation explanation of colour-grapheme synaesthesia (e.g., see Brang et al. 2011; Hubbard et al. 2011; Ramachandran and Hubbard 2001a), adjacent brain areas may exhibit an enhanced susceptibility to neural cross-activation. That said, while such adjacency might well predict interactions between those features processed in these two regions, it is worth noting that tactile shape information is processed elsewhere (e.g., see De Santis et al. 2007; Van Boven et al. 2005), thus making this a somewhat unlikely account of any taste/flavour-shape matching. Moreover, the contiguity hypothesis would not explain the transitivity with auditory representations that we noted earlier.

Studies on other crossmodal matchings conducted using functional neuroimaging or transcranial magnetic stimulation (TMS) suggest that the crucial locus for inter-modal connections (at least in the audiovisual case) is rather multisensory integration in areas such as intraparietal sites (Bien et al. 2012). Again, the similarity with the characteristics identified for neurological cases of synaesthesia (Muggleton et al. 2007) does not seem to have to win the comparison too easily: If the intraparietal areas are active both in synaesthetes and in everyone else, it is not exactly the same zones of these areas which are at stake in both of these cases. Regarding the difference between crossmodal correspondences and semantically-mediated transfers, not much has been done yet in the domain of shape-flavours, but preliminary results in the audio-visual domain show that different neural substrates are also likely to be involved in different types of crossmodal connections (Sadaghiani et al. 2009).

An alternative account might be to posit that stimuli that are somehow related to danger might be matched. Note here that angular shapes light up the fear circuits of the amygdala (cf. Bar and Neta 2006; Shenhav et al. 2013); Similarly, bitterness and carbonation were, evolutionarily speaking, presumably both associated with foods that were poisonous, or overripe, and hence presumably to be avoided because of their potential danger (e.g., Glendinning 1994).

\section{Conclusions}

As the recent evidence reviewed in this article has hopefully made clear, the use of shape terms to describe the tastes, aromas, flavours, and oral- 
somatosensory textures of foods represents more than merely the metaphorical use of language. Flavours and tastes are intimately related to representations of shapes. Contrary to what Peirce's (1868) initial quote suggested, seeing certain shapes can also elicit, or prime, representations of tastes and flavours.

While a few synaesthetes may experience crossmodal associations in an especially vivid and consistent manner (e.g., Cytowic and Wood 1982), and some use shape descriptors in a metaphorical manner, careful empirical investigation has now started to reveal that we all match a variety of tastes, flavours, and oral-somatosensory food and beverage attributes to shapes/forms in a manner that is both reliable and non-random. That is, the crossmodal mapping (or correspondence) between shapes and tastes, flavours, and the oral-somatosensory attributes of foods is both a ubiquitous and robust phenomenon across the general population. The fact that such correspondences typically (and here is where they contrast with synaesthesia) do not give rise to an extra-sensory experience does not mean that they are not important and do not have the power to subtly affect our everyday experience of food and drink.

What is more, once one knows about the shapes of tastes, aromas, flavours, and oral-somatosensory textures, and its impact on people's rating or experience, then one can potentially use such insights in order to influence, and potentially enhance, the consumer's experience of food and drink. Now, while some of this has undoubtedly been going on for years (especially in the field of marketing; e.g., Dichter 1974; Spence 2012), we predict an explosion of innovation in this area given the recent rise of molecular gastronomy, not to mention the rapid innovation we are now seeing in packaging/plateware design (Piqueras-Fiszman and Spence 2012; Spence 2013; Spence and Piqueras-Fiszman 2012, in press).

In terms of the theoretical import of this kind of research, it can be argued that the investigation of shape-taste/aroma/texture/flavour associations highlights the need to distinguish between synaesthesia, metaphorical transfers, crossmodal correspondences, and sound symbolism - labels which are sometimes used indifferently or considered closer than they may actually be (see Marks 2011).

It is important to note that the neuroscientific investigation of what were before nothing more than mere lucky guesses (or intuitive designs) does more than merely give respectability, explanation, and better predictability to the shape-taste relations. By anchoring it in our perceptual (and emotional) systems, it also opens up a number of fascinating and important questions as to the regularity of these matchings across different age groups and cultures (see Bremner et al. 2013; Henrich et al. 2010; Piqueras-Fiszman et al. 2012; 
Woods et al. 2013), not to mention across different species (cf. Ludwig et al. 2011), thus supporting the idea that flavour experience should adapt more to the specific tastes and expectations of the diners (cf. DeRosia 2008).

\section{References}

Auvray, Malika and Charles Spence. 2008. "The multisensory perception of flavor." Consciousness and Cognition 17: 1016-1031.

Bar, Moshe and Maital Neta. 2006. "Humans prefer curved visual objects." Psychological Science 17: 645-648.

Bartoshuk, Linda M. 1980. "Separate worlds of taste." Psychology Today 14: 48-49, $51,54-56,63$.

Baudelaire, Charles. 1857. Les Fleurs du mal [Flowers of evil]. Paris: PouletMalassis.

Becker, Liza, Thomas J. L. van Rompay, Hendrik N. J. Schifferstein and Mirjam Galetzka. 2011. "Tough package, strong taste: The influence of packaging design on taste impressions and product evaluations." Food Quality and Preference 22: 17-23.

Beeli, Gian, Michaela Esslen and Lutz Jäncke. 2005. "When coloured sounds taste sweet." Nature 434: 38.

Bertolli, Paul. 2003. Cooking by hand. New York: Clarkson Potter.

Bien, Nina, Sanne ten Oever, Rainer Goebel and Alexander T. Sack. 2012. "The sound of size: Crossmodal binding in pitch-size synesthesia: A combined TMS, EEG, and psychophysics study." NeuroImage 59: 663-672.

Bremner, Andrew J., Serge Caparos, Jules Davidoff, Jan de Fockert, Karina J. Linnell and Charles Spence. 2013. "'Bouba' and 'Kiki' in Namibia? A remote culture make similar shape-sound matches, but different shape-taste matches to Westerners." Cognition 126: 165-172.

Cheskin, Louis. 1967. Secrets of marketing success: An expert's view on the science and art of persuasive selling. New York: Trident Press.

Cliff, Margaret and Ann C. Noble. 1990. "Time-intensity evaluation of sweetness and fruitiness and their interaction in a model solution." Journal of Food Science 55: 450-454.

Crisinel, Anne-Sylvie, Sophie Jones and Charles Spence. 2012. "The sweet taste of maluma': Crossmodal associations between tastes and words." Chemosensory Perception 5: 266-273.

Crisinel, Anne-Sylvie and Charles Spence. 2012. "A fruity note: Crossmodal associations between odors and musical notes." Chemical Senses 37: 151-158.

Crisinel, Anne-Sylvie and Charles Spence. 2010. "As bitter as a trombone: Synesthetic correspondences in non-synesthetes between tastes and flavors 
and musical instruments and notes." Attention, Perception, \& Psychophysics 72: 1994-2002.

Crisinel, Anne-Sylvie and Charles Spence. 2011. "Crossmodal associations between flavoured milk solutions and musical notes.” Acta Psychologica 138: 155-161. Cytowic, Richard E. 1993. The man who tasted shapes. USA: G. P. Putnam's Sons. Cytowic, Richard E. and David M. Eagleman. 2009. Wednesday is indigo blue: Discovering the brain of synesthesia. Cambridge, MA: MIT Press.

Cytowic, Richard E. and Frank B. Wood. 1982. "Synaesthesia II: Psychophysical relations in the synaesthesia of geometrically shaped taste and colored hearing." Brain and Cognition 1: 36-49.

Davidson, Jeffrey M., Robert S. T. Linforth, Tracey Ann Hollowood and Andrew J. Taylor. 1999. "Effect of sucrose on the perceived flavor intensity of chewing gum." Journal of Agriculture \& Food Chemistry 47: 4336-4340.

Day, Sean A. 2005. Some demographic and socio-cultural aspects of synesthesia. In Lynn C. Robertson and Noam Sagiv (eds.). Synesthesia: Perspectives from cognitive neuroscience, 11-33. New York: Oxford University Press.

Day, Sean A. 2011. "The human sensoria and a synaesthetic approach to cooking. Collapse VII: $378-409$.

DeRosia, Eric D. 2008. "The effectiveness of nonverbal symbolic signs and metaphors in advertisements: An experimental inquiry." Psychology and Marketing 25: 298-316.

Deroy, Ophelia, Anne-Sylvie Crisinel and Charles Spence. 2013. "Crossmodal correspondences between odors and contingent features: Odors, musical notes, and geometrical shapes." Psychonomic Bulletin \& Review. doi 10.3758/ s13423-013-0397-0

Deroy, Ophelia and Charles Spence. (in press). Borderline cases of crossmodallyinduced experiences. In Ophelia Deroy (ed.). Sensory blending: New essays on synaesthesia. Oxford: Oxford University Press.

Deroy, Ophelia and Charles Spence. 2013. "Weakening the case for "weak synaesthesia': Why crossmodal correspondences are not synaesthetic." Psychonomic Bulletin \& Review 20: 643-664.

Deroy, Ophelia, and Dominique Valentin. 2011. "Tasting liquid shapes: Investigating cross-modal correspondences. Chemosensory Perception 4: 80-90.

De Santis, Laura, Lucas Spierer, Stephanie Clarke and Micah M. Murray. 2007. "Getting in touch: Segregated somatosensory what and where pathways in humans revealed by electrical neuroimaging." NeuroImage 37: 890-903.

Dichter, Ernest. 1971. "The strategy of selling with packaging." Package Engineering Magazine, July: 16a-16c.

Evans, Gareth. 1982. The varieties of reference (published posthumously, edited by John McDowell). Oxford: Oxford University Press.

Evans, Karla K. and Anne Treisman. 2010. "Natural cross-modal mappings between visual and auditory features." Journal of Vision 10.1: 1-12.

Ferrari, G. C. 1907. "Una varieta nuova di sinestesia" [A new variety of synaesthesia]. Rivista di Psicologia 3: 297-317. 
Gagnaire, Pierre and Chilly Gonzales. 2010. Bande originale. 175 Recettes \& une heure de musique [Bande Originale. 175 recipes and an hour of music]. Paris: Flammarion.

Gal, David, S. Christian Wheeler and Baba Shiv. 2007. Cross-modal influences on gustatory perception. Unpublished manuscript available at SSRN: http:// ssrn.com/abstract $=1030197$

Gallace, Alberto, Erica Boschin and Charles Spence. 2011. "On the taste of 'Bouba' and 'Kiki': An exploration of word-food associations in neurologically normal participants." Cognitive Neuroscience 2: 34-46.

Gallace, Alberto, Mary K. Ngo, John Sulaitis and Charles Spence. 2012. Multisensory presence in virtual reality: Possibilities and limitations. In George Ghinea, Frederic Andres, and Stephen Gulliver (eds.). Multiple sensorial media advances and applications: New developments in MulSeMedia, 1-40. Hershey, PA: IGI Global.

Ginsberg, Leon. 1923. "A case of synaesthesia." American Journal of Psychology 34: 582-589.

Glendinning, John I. 1994. "Is the bitter rejection response always adaptive?" Physiology \& Behavior 56: 1217-1227.

Gómez Milan, Emilio, Oscar Iborra, Maria José de Cordoba, V. Juárez-Ramos, M. A. Rodríguez Artacho and J. L. Rubio. 2013. "The Kiki-Bouba effect: A case of personification and ideaesthesia." Journal of Consciousness Studies 20: 84-102.

Grice, Herbert Paul. 1957. "Meaning." The Philosophical Review 66: 377-388.

Hanson-Vaux, Grant, Anne-Sylvie Crisinel and Charles Spence. 2013. "Smelling shapes: Crossmodal correspondences between odors and shapes." Chemical Senses 38: 161-166.

Harrison, John. 2001. Synaesthesia: The strangest thing. Oxford: Oxford University Press.

Henrich, Joseph, Steven J. Heine and Ara Norenzayan. 2010. "The weirdest people in the world?" Behavioral and Brain Sciences 33: 61-135.

Hirsch, Jesse. 2011. "A fine tune to match your entrée." New York Times, 22 July. [Online], Available: http://www.nytimes.com/2011/07/22/us/22bcculture. html?_r=0 [10 June 2013].

Holt-Hansen, Kristian. 1976. "Extraordinary experiences during cross-modal perception." Perceptual and Motor Skills 43: 1023-1027.

Holt-Hansen, Kristian. 1968. "Taste and pitch." Perceptual and Motor Skills 27: 59-68.

Hubbard, Edward M., David Brang and Vilayanur S. Ramachandran. 2011. "The cross-activation theory at 10." Journal of Neuropsychology 5: 152-157.

Huysmans, Joris-Karl. 1884. À rebours [Against nature]. Paris: Charpentier.

Knöferle, Klemens M. and Charles Spence. 2012. "Crossmodal correspondences between sounds and tastes." Psychonomic Bulletin \& Review 19: 992-1006.

Köhler, Wolfgang. 1929. Gestalt psychology. New York: Liveright. 
Köhler, Wolfgang. 1947. Gestalt psychology: An introduction to new concepts in modern psychology. New York: Liveright Publication.

Kosslyn, Stephen M., Marlene Behrmann and Marc Jeannerod. 1995. "The cognitive neuroscience of mental imagery." Neuropsychologia 33: 1335-1344.

Köster, Egon P. 2003. "The psychology of food choice: Some often encountered fallacies." Food Quality and Preference 14: 359-373.

Lakoff, George, and Mark Johnson. 1980. Metaphors we live by. Chicago, IL: University of Chicago Press.

Lehrer, Adrienne. 2009. Wine and conversation ( $2^{\text {nd }}$ Ed.). Oxford: Oxford University Press.

Liang, Pei, Soumyajit Roy, Meng-Ling Chen and Gen-Hua Zhang. 2013. "Visual influence of shapes and semantic familiarity on human sweet sensitivity." Behavioural Brain Research 253: 42-47.

Liu, Chang Hong and John M. Kennedy. 1997. "Form symbolism, analogy, and metaphor. Psychonomic Bulletin \& Review 4: 546-551.

Liu, Hugo, Matthew Hockenberry and Ted Selker. 2005. Synesthetic recipes: Foraging for food with the family, in taste-space. Proceedings of SIGGRAPH '05 ACM.

Ludwig, Vera U., Ikuma Adachi and Tetsuro Matzuzawa. 2011. "Visuoauditory mappings between high luminance and high pitch are shared by chimpanzees (Pan troglodytes) and humans." Proceedings of the National Academy of Sciences USA 108: 20661-20665.

Luria, Aleksandr Romanovich. 1968. The mind of a mnemonist. New York: Basic Books.

Marinetti, Filippo Tommaso. 1930/1989. The futurist cookbook (Trans. S. Brill). San Francisco: Bedford Arts.

Marks, Lawrence E. 1991. Metaphor and the unity of the senses. In Harry T. Lawless and Barbara P. Klein (eds.), Sensory science theory and applications in foods, 185-205. New York: Marcel Dekker.

Marks, Lawrence E. 2011. "Synesthesia, then and now." Intellectica 55: 47-80.

Mesz, Bruno, Mariano Sigman and Marcos A. Trevisan. 2012. "A composition algorithm based on crossmodal taste-music correspondences." Frontiers in Human Neuroscience 6: 1-6.

Mesz, Bruno, Marcos A. Trevisan and Mariano Sigman. 2011. "The taste of music." Perception 40: 209-219.

Muggleton, Neil, Elias Tsakanikos, Vincent Walsh and Jamie Ward. 2007. "Disruption of synaesthesia following TMS of the right posterior parietal cortex.” Neuropsychologia 45: 1582-1585.

Myers, Charles S. 1911. "A case of synaesthesia." British Journal of Psychology 4: 228-238.

Ngo, Mary Kim, Reeva Misra and Charles Spence. 2011. "Assessing the shapes and speech sounds that people associate with chocolate samples varying in cocoa content." Food Quality \& Preference 22: 567-572. 
Ngo, Mary Kim, Betina Piqueras-Fiszman and Charles Spence. 2012. "On the colour and shape of still and sparkling water: Insights from online and laboratorybased testing." Food Quality \& Preference 24: 260-268.

Ngo, Mary Kim and Charles Spence. 2011. "Assessing the shapes and speech sounds that people associate with different kinds of chocolate." Journal of Sensory Studies 26: 421-428.

Ngo, Mary Kim, Carlos Velasco, Alejandro Salgado, Emilia Boehm, Daniel O'Neill and Charles Spence. 2013. "Assessing crossmodal correspondences in exotic fruit juices: The case of shape and sound symbolism." Food Quality \& Preference 28: 361-369.

Overbeeke, C. J. and M. E. Peters. 1991. “The taste of desserts' packages." Perceptual and Motor Skills 73: 575-583.

Parise, Cesare V. and Charles Spence. 2012. "Audiovisual crossmodal correspondences and sound symbolism: An IAT study." Experimental Brain Research 220: 319-333.

Peirce, Charles S. (1857-1866/1982). Writings of Charles S. Peirce; A chronological edition. Volume I, 1857-1866; M. H. Fisch (ed.). Bloomington, Indiana: UP.

Peynaud, Emile. 1996. The taste of wine: The art and science of wine appreciation. New York: John Wiley \& Sons.

Piesse, G. W. Septimus. 1891. Piesse's The art of perfumery ( $5^{\text {th }}$ Ed.). London: Piesse and Lubin. Downloaded from http://www.gutenberg.org/files/16378/16378h/16378-h.htm

Piqueras-Fiszman, Betina, Jorge Alcaide, Elena Roura and Charles Spence. 2012. "Is it the plate or is it the food? Assessing the influence of the color (black or white) and shape of the plate on the perception of the food placed on it." Food Quality and Preference 24: 205-208.

Piqueras-Fiszman, Betina and Charles Spence. (2012a). "Sensory incongruity in the food and beverage sector: Art, science, and commercialization." Petits Propos Culinaires 95: 74-118.

Rader, Charles M. and Auke Tellegen. 1987. "An investigation of synesthesia." Journal of Personality and Social Psychology 52: 981-987.

Ramachandran, Vilayanur S. and Edward M. Hubbard. 2003. "Hearing colors, tasting shapes." Scientific American 288 (May): 43-49.

Ramachandran, Vilayanur S. and Edward M. Hubbard. (2001a). "Psychophysical investigations into the neural basis of synaesthesia." Proceedings of the Royal Society London, B. 268: 979-983.

Ramachandran, Vilayanur S. and Edward M. Hubbard. (2001b). "Synaesthesia A window into perception, thought and language." Journal of Consciousness Studies 8: 3-34.

Rudmin, Floyd and Mark Cappelli. 1983. "Tone-taste synesthesia: A replication." Perceptual and Motor Skills 56: 118.

Sadaghiani, Sepideh, Joost X. Maier and Uta Noppeney. 2009. "Natural, metaphoric, and linguistic auditory direction signals have distinct influences on visual motion processing." The Journal of Neuroscience 29: 6490-6499. 
Seo, Han-Seok, Artin Arshamian, Kerstin Schemmer, Ingeborg Scheer, Thorsten Sander, Guido Ritter and Thomas Hummel. 2010. "Cross-modal integration between odors and abstract symbols." Neuroscience Letters 478: 175-178.

Shenhav, Amitai, Lisa Feldman Barrett and Moshe Bar. 2013. "Affective value and associative processing share a cortical substrate." Cognitive, Affective, \& Behavioural Neuroscience 13: 46-59.

Spence, Charles. 2011. "Crossmodal correspondences: A tutorial review." Attention, Perception, \& Psychophysics 73: 971-995.

Spence, Charles. 2012a. "Managing sensory expectations concerning products and brands: Capitalizing on the potential of sound and shape symbolism." Journal of Consumer Psychology 22: 37-54.

Spence, Charles. 2012b. "Synaesthetic marketing: Cross sensory selling that exploits unusual neural cues is finally coming of age." The Wired World in 2013, November: 104-107.

Spence, Charles and Alberto Gallace. 2011. "Tasting shapes and words." Food Quality and Preference 22: 290-295.

Spence, Charles, Vanessa Harrar and Betina Piqueras-Fiszman. 2012. "Assessing the impact of the tableware and other contextual variables on multisensory flavour perception." Flavour 1: 7 .

Spence, Charles and Mary Kim Ngo. 2012. "Assessing the shape symbolism of the taste, flavour, and texture of foods and beverages." Flavour 1: 12.

Spence, Charles, Mary Kim Ngo, Bronwen Percival and Barry Smith. 2013. "Crossmodal correspondences: Assessing the shape symbolism of foods having a complex flavour profile.” Food Quality and Preference 28: 206-212.

Spence, Charles and Betina Piqueras-Fiszman. 2012. The multisensory packaging of beverages. In Michael G. Kontominas (ed.). Food packaging: Procedures, management and trends, 187-233. Hauppauge NY: Nova Publishers.

Spence, Charles and Betina Piqueras-Fiszman. (in press). The perfect meal: the multisensory science of food and dining. Oxford: Wiley-Blockwell.

Stevens, Stanley Smith. 1966. "Matching functions between loudness and ten other continua." Perception and Psychophysics 1: 5-8.

Stevenson, Richard J. and Caroline Tomiczek. 2007. "Olfactory-induced synesthesias: A review and model." Psychological Bulletin 133: 294-309.

Stewart, Peter C. and Erica Goss. 2013. "Plate shape and colour interact to influence taste and quality judgments. Flavour 2: 27.

Uznadze, Dimitri. 1924. "Ein experimenteller Beitrag zum Problem der psychologischen Grundlagen der Namengebung" [An experimental contribution to the problem of the psychological foundations of naming]. Psychologische Forschung 5.1-2: 24-43.

Uznadze, Dimitri. 1927. Zum Problem der Bedeutungserfassung [On the problem of determining meaning]. Proceedings and Papers of the VIII International Congress of Psychology, Groningen, 6-11 September, 1926, 440-442. P. Noordhoff-Groningen. 
van Boven, Robert W., John E. Ingeholm, Michael S. Beauchamp, Philip C. Bikle and Leslie G. Ungerleider. 2005. "Tactile form and location processing in the human brain." Proceedings of the National Academy of Sciences USA 102: 12601-12605.

Velasco, Carlos, Russell Jones, Scott King, R. Dove, J. Kellie and Charles Spence. (submitted). "Smelling a sweet tune? Assessing the influence of soundscapes on the perception of fragrance." Chemosensory Perception.

Velasco, Carlos, Russell Jones, Scott King and Charles Spence. 2013. "Assessing the influence of the multisensory environment on the whisky drinking experience." Flavour 2: 23.

Walker, Peter and Laura Walker. 2012. "Size-brightness correspondence: Crosstalk and congruity among dimensions of connotative meaning." Attention, Perception, \& Psychophysics 74: 1226-1240.

Wang, R. W. Y. and C. H. Sun. (2006). "Analysis of interrelations between bottle shape and food taste." Paper presented at the 2006 Design Research Society, International Conference in Lisbon (IADE), p. 13. Downloaded from http:// www.iade.pt/drs2006/wonderground/proceedings/fullpapers/DRS2006_0054. pdf

Ward, Jamie. 2008. The frog who croaked blue: Synesthesia and the mixing of the senses. New York: Routledge.

Ward, Jamie, Samantha Moore, Daisy Thompson-Lake, Shireen Salih and Brianna Beck. 2008a. "The aesthetic appeal of auditory-visual synaesthetic perceptions in people without synaesthesia." Perception 13: 1285-1297.

Ward, Jamie, and Julia Simner. 2003. "Lexical-gustatory synaesthesia: Linguistic and conceptual factors." Cognition 89: 237-261.

Ward, Jamie, Daisy Thompson-Lake, Roxanne Ely and Flora Kaminski. 2008b. "Synaesthesia, creativity and art: What is the link?" British Journal of Psychology 99: 127-141.

Weiss, Allen S. 2002. Feast and folly: Cuisine, intoxication and the poetics of the sublime. Albany, NY: State University of New York Press.

White, Paul. 2008. "Food of love: Wine and music." The World of Fine Wine 21: $120-123$.

Williams, Joseph M. 1976. "Synesthetic adjectives: A possible law of semantic change." Language 52: 461-478.

Woods, Andy T., Charles Spence, Natalie Butcher and Ophelia Deroy. 2013. "Fast lemons and sour boulders: Testing the semantic hypothesis of crossmodal correspondences using an internet-based testing methodology." i-Perception 4: 365-369. 